\title{
Critical Leg Ischemia Following Abdominal Aortic Aneurysm Occlusion
}

\author{
Shun-ichi Kawarai, Keisuke Kanda, Masaharu Hatakeyama and Koichi Nagaya
}

Key words: abdominal aortic aneurysm, thrombosis, leg ischemia

(Intern Med 56: 2681, 2017)

(DOI: 10.2169/internalmedicine.8876-17)
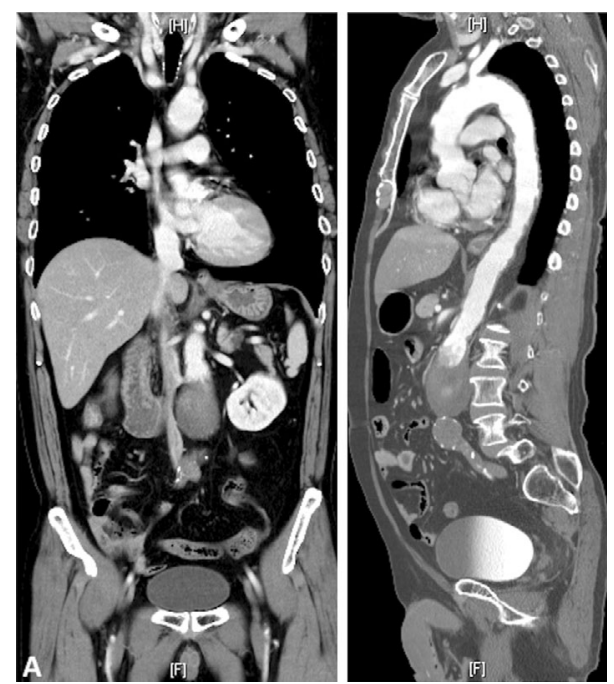

Picture 1.

A 67-year-old man with hypertension and without a history of claudication was admitted to our hospital with ongoing bilateral leg numbness after persistent nausea and vomiting of a few days in duration. On arrival, his legs were paralyzed with remarkable hypothermia and livedo reticularis up to the umbilicus. Contrast-enhanced computed tomography revealed an infrarenal bimodal abdominal aortic aneurysm (AAA) with total occlusion by intra-aneurysmal thrombosis (Picture 1). To reestablish leg perfusion, emergency bilateral axillofemoral bypass was performed without delay. Transient postoperative hemodialysis was required for acute renal failure following reperfusion injury. The patient gradually regained sensation in the leg and was ambulatory on discharge after intense rehabilitation. The bypass grafts were patent and the AAA remained occluded (Picture 2).

Critical leg ischemia due to a thrombosed AAA is extremely rare with $<50$ reported cases (1). A prompt diagno-

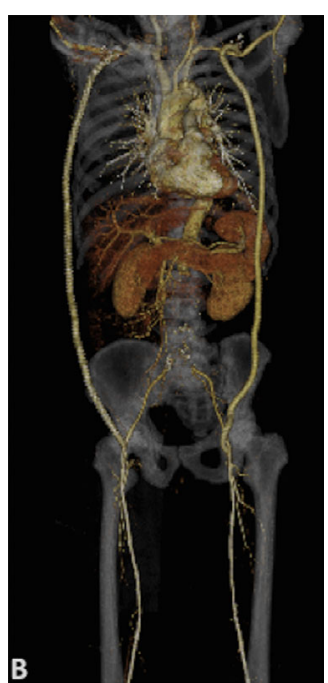

Picture 2.

sis and immediate revascularization by surgical or endovascular intervention, is mandatory for avoiding catastrophic outcomes (2).

The authors state that they have no Conflict of Interest (COI).

\section{References}

1. Hirose $\mathrm{H}$, Takagi M, Hayashiba $\mathrm{H}$, et al. Acute occlusion of an abdominal aortic aneurysm. Angiology 51: 515-523, 2000.

2. Robinson WP, Patel RK, Columbo JA, et al. Contemporary management of acute aortic occlusion has evolved but outcomes have not significantly improved. Ann Vasc Surg 34: 178-186, 2016.

The Internal Medicine is an Open Access article distributed under the Creative Commons Attribution-NonCommercial-NoDerivatives 4.0 International License. To view the details of this license, please visit (https://creativecommons.org/licenses/ by-nc-nd/4.0/).

Department of Cardiovascular Surgery, Aomori Prefectural Central Hospital, Japan

Received: January 16, 2017; Accepted: February 8, 2017; Advance Publication by J-STAGE: September 6, 2017

Correspondence to Dr. Shun-ichi Kawarai, shun_kawa@med.pref.aomori.jp

(C) 2017 The Japanese Society of Internal Medicine. Intern Med 56: 2681, 2017 